\title{
Towards Consistency: Digital Learning Thresholds
}

\section{Ashraf, William ${ }^{\mathrm{a}}$; Barry, Wayne ${ }^{\mathrm{a}}$ and McFarlane, Sam ${ }^{\mathrm{a}}$}

${ }^{a}$ Learning and Teaching Enhancement, Canterbury Christ Church University, UK.

\begin{abstract}
We report on the development of CCCU Digital Learning Thresholds (DLT). The principle aim of DLT is that all CCCU students have access to digital learning, and that all staff and students will have clear expectations about how, why and when to use digital learning. In addition DLT also align with and supports the VLE consistency agenda. Furthermore, we have developed an innovative evaluation framework to assess the success of our DLT as well proposing their integrating into a blended learned model which emcompasses a quality assurance and enhancement pathway.
\end{abstract}

Keywords: digital learning thresholds; learning platform; consistency; student experience; blended learning model. 


\section{Introduction}

The Virtual Learning Environment (VLE) is a core learning system used by all Higher Education Institutions (HEIs), not just to provide more flexible approaches to learning in order to meet the challenges of students who may be learning in different modes, places and paces (Gordon, 2014); but as a vehicle which carry the learning and teaching materials, information, activites and resources for all types of programmes. Canterbury Christ Church University (CCCU) has used the Blackboard VLE since 2002, that has seen use being deployed across all academic programmes.

However, there has been a strong argument and rationale for the University to adopt and adhere to a more consistent approach on how the VLE is being used and how the student population are able to engage with it. The rational for consistency is not just local to CCCU; a significant number of HEIs in the United Kingdom (UK) are striving ahead implementing their own more ambitious consistency and "baseline" practices in response to student and staff feedback (Reed, 2014, May 7).

The paper begins by introducing the notion of consistency and how this has affected UK HEIs and students before looking at the CCCU experience. The paper goes on to outline an approach to embedding VLE consistency called Digital Learning Thresholds (DLT) that is being developed and driven by the University's Learning Technology Team based upon the work originally undertaken by the first author at a previous instiution in Australia.

\section{Consistency}

\subsection{The UK HE Sector Experience}

The Heads of e-Learning Forum (HeLF) is a network of senior staff in institutions who have a strategic responsibility to promoting, supporting and developing technology enhanced learning (TEL). There are currently 135 nominated Heads from UK HEIs within the forum who, collectively, have a very powerful voice in the way that TEL is being used and driven in the UK HE sector.

A recent survey was conducted by HeLF to gather information on which institutions had adopted a "minimum standards" or consistency approach (Reed, 2014, March 21). Whilst the survey attracted a low response, $18 \%$ (n:24), it was nevertheless highlighted that $75 \%$ (n:18) of the respondents had already applied consistency within their VLE, whilst $25 \%$ (n:6) were considering introducing such standards in the future (ibid.). For most institutions, the "minimum standards" comprised of staff profiles, learning outcomes, recommended readings, assessment requirements, lecture handouts followed by announcements and a timetable. 
However, it is recognized that such an undertaking can present an additional workload for staff. One solution is to have a technical integration between the VLE and various Management Information Systems (MIS) that has the capacity to harvest many of the criteria for consistency from existing data stores (Reed \& Watmough, 2015:86). This could include, for example, pulling information from human resources databases to populate staff on the course, reading lists from the library, past exam paper and handbooks on the curriculum system as well as timetabling from a central rooming system. The information can then be updated dynamically and allows staff to focus on enhancing learning and teaching rather than the administration of the course. Needless to say, such an enterprise requires considerable planning and development with senior management sponsorship supported by policies and guidelines being critical factors in the successful implementation of a "minimum standards" project (Ellis \& Calvo, 2007).

\subsection{The UK Student Experience}

The notion of introducing a "minimum standards" for the VLE may, on the surface, appear to be quite a simple, if 'low-tech', solution. However, the effects of inconsistent layout, structure and naming conventions between modules in an institutional VLE is a "significant factor for [student] dissatisfaction" (Bee, 2013:6), with similar examples of "disparity of usage" from the 'student voice' being found across the UK HE sector (Ahmed \& Morley, 2010) through student evaluation mechanism, such as the UK's annual National Student Survey (NSS) (HEFCE, 2015).

In the field of Human-Computer Interaction (HCI) and, in particular, Usability Studies, the notion of consistency, in terms of naming conventions and the location of links and content , and it's relationship with cognition can determine how (dis)engaged / (dis)interested a user is with a particular interface (Martin-Michiellot \& Mendelsohn, 2000; Rovai, 2004; Nielson, 2011). Furthermore, consistency creates a perception of trust, reliability and professionalism that can have an affect upon a user's experience with an organisation - the more consistent the user experience, the more positive the user feels about the organisation (Estes, 2013) - this is what students have come to expect of their universities when using the VLE.

\subsection{The CCCU Experience}

Blackboard, the VLE at CCCU was first introduced as an enhancement tool for learning and teaching in 2002. It currently hosts 20,000 students and 4,000 staff users with a Blackboard site for nearly very academic course that is running, as of December 2015, there are over 2000 active Blackboard sites. It is unsurprising, therefore, that there has been 
a growing voice amongst CCCU's student population in the NSS surveys as well as CCCU's annual student survey that the current structure of Blackboard sites (known locally as boards) are becoming increasingly difficult to use and navigate.

Blackboard personally has been a negative part so far. It's confusing in regards to finding work which has been set... (CCCU student, 2015)

One of the reasons identified is the use of non-standard language, for example, submission areas being called Turnitin buckets, e-submission, electronic submission, or assignments, etc. Student feedback has also indicated that some assignments were submitted late due to confusion concerning the "submission points" and their exact location. There is also frequent frustration that Blackboard sites tend to be configured differently across different courses as well as implementing inconsistent folder structures within and between different sites.

Further evidence of the impact of inconsistent Blackboard sites is reflected in the number of student 'help desk' calls that CCCU received during the 2015 calendar year (January to December), where almost 900 calls were received from students requesting assistance in trying to locate content from within their Blackboard site.

\section{Digital Learning Thresholds}

Building upon the earlier work of the University's Technology Enhanced Learning and Teaching (TELT) Strategy (CCCU, 2012), the Digital Learning Thresholds (DLT) is conceived as a method for tutors to develop their digital learning environments in ways that actively support the student learning experience which increases their online activity and engagement with digital technologies, and is constructively aligned with the University's Learning, Teaching \& Assessment Strategy (CCCU, 2015), as well as addressing the issue of consistency.

We redefined the digital learning environment as a 'Learning Platform', which is a conglomeration of core learning technologies (e.g. VLE, e-portfolio, lecture capture, web conferencing, media streaming, e-submission \& e-feedback, etc.) being used to support learning, teaching and assessment. The notion of the DLT was being developed at the University of Wollongong, New South Wales, Australia by the first author (UoW, 2015) following on from developments at Kings College London. 
Table 1. The Digital Learning Thresholds (DLT)

\begin{tabular}{l|c|c|c}
\hline \multirow{2}{*}{ Learning Platform Activities } & \multicolumn{2}{|c}{ Digital Learning Thresholds } \\
\cline { 2 - 4 } & $\begin{array}{c}\text { Stage I } \\
(\mathbf{2 0 1 6 / 1 7 )}\end{array}$ & $\begin{array}{c}\text { Stage II } \\
(\mathbf{2 0 1 7 / 1 8 )}\end{array}$ & $\begin{array}{c}\text { Best } \\
\text { Practice }\end{array}$ \\
\hline A) Module Information & & & \\
\hline B) Assessment \& Feedback & & & \\
\hline C) Content & & & \\
\hline D) Communication & & & \\
\hline E) Collaboration & & & \\
\hline F) Evaluation & & & \\
\hline G) Technical & & & \\
\hline
\end{tabular}

The DLT comprises of two digital learning thresholds, Stages I \& II and Best Practice, and seven learning platform activites (A to G) (see Table 1 above). Stages I \& II will be phased over two academic years and is mandatory across all modules. The "Best Practice" threshold is optional. The two digital learning thresholds provide opportunities for the tutor to challenge and transform the student learning experience using a range of appropriate technologies. Whereas, the seven learning platform activities will aid with the increase of the student learning experience, by providing a technology enriched curriculum, which can equip them with the necessary skillset in readiness for graduate and professional employment.

The learning platform activities not only provide different opportunities for students to engage in with different digital technologies (beyond the Blackboard VLE), it also offers tutors with a framework and guidance in structuring their VLE sites in a consistent manner in terms of structure, layout and naming conventions, as the following list entails:

- Module Information would include module handbook, reading lists, learning outcomes and key dates.

- Assessment \& Feedback provides details of assessment tasks and offer opportunities to use different forms of electronic assessment such as online tests, blogs and wikis.

- Content refers to those lecture and seminar notes and materials and places responsibility on teaching teams to ensure that the materials are compliant with copyright and accessibility requirements. 
- Communication ensures that there is a welcome message on every VLE site and that students know who they can contact within the teaching and admin teams.

- Collaboration provides opportunities to use a range of tools to support discussions and team-based activities, such as discussion boards and wikis.

- Evaluation is concerned with provided tools (i.e. learning analytics) and methods (i.e. anonymous student survey) to ensure the quality and consistency of the module and teaching. This funtion tends to be 'time released' at specific points in the academic year or duration of the module.

- Technical encourages programme teams to perform a 'health check' on their VLE sites to ensure that the links works, the content meets accessibility standards and than student work, marks and feedback are archived and stored properly.

The Learning Platform (see Figure 1 below), therefore, introduces students to a consistent digital presence (Stage I, e.g. students submitting their essays electronically); through the engagement and interaction with appropriate technologies, students are enabled to become more responsible for key areas of their learning (Stage II, e.g. students engaging with an online test), which underpin more sophisticated and authentic activities that will develop student employability (Chatterton \& Rebbeck, 2015) and prepare them for professional working environments (Best Practice, e.g. students collaboratively working using simulation software).

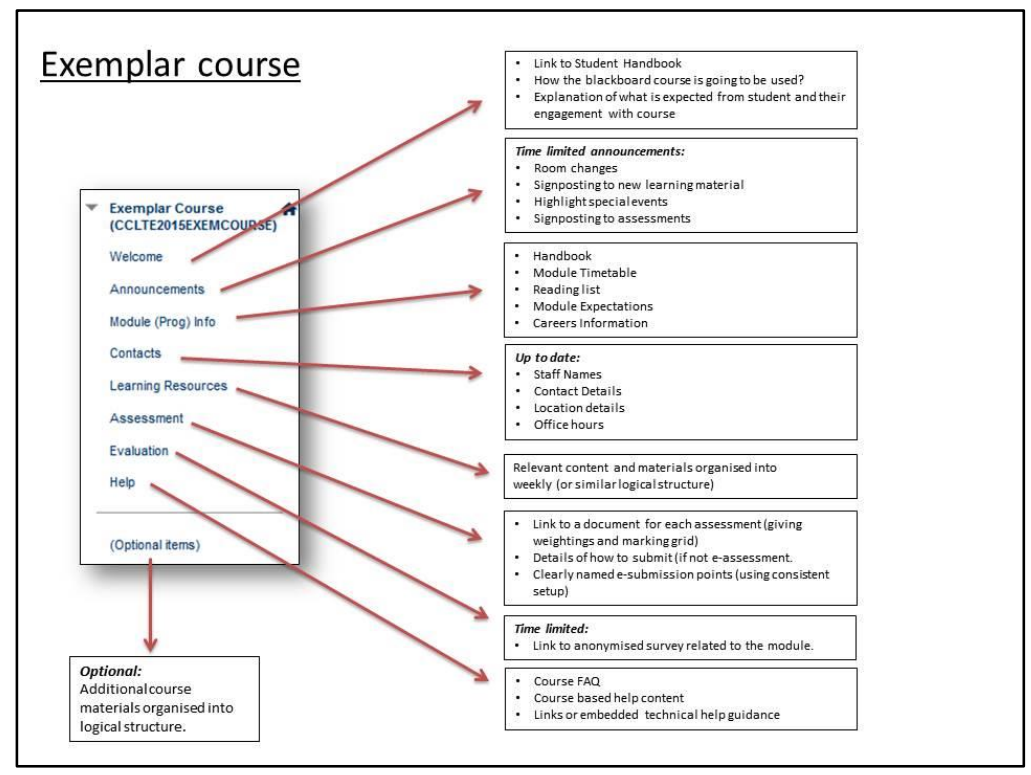

Figure 1. An exemplar VLE site layout at CCCU 


\subsection{DLT Implementation}

The DLT has been designed to increase the digital learning experience of students through the incorporation of essential and good practices in digital learning. An institutionallyagreed "checklist" provides an overview of the key digital threshold elements and practical strategies for implementation. This "checklist" can be used by Programme Directors and/or Module Leaders for self-review, or by Faculties (via their Faculty Director of Learning \& Teaching) for reviewing purposes. Furthermore, the "checklist" offers tutors an opportunity to reflect upon how they are using the Learning Platform and to consider some ideas on how to create stimulating, organised and well-resourced digital learning environments that supports and complements traditional face-to-face teaching. This project will be evaluated using the Context, Input, Process, and Product (CIPP) Evaluation Model (Shufflebeam, 2003) to gather feedback from stakeholders and users.

\section{Conclusion}

Our work has demonstrated that the introduction of large scale institution change regarding consistency and DLT requires robust mechanisms for staff communication, change agents and senior executive committemments to increase our capacity, capability and confidence in the effective deployment, utilization and evalution of learning technologies in order to increase academic adoption. Additionally, our work represents a compelling case for change, in an area that has been nelegected, and represents a significant step-change towards enhancieng the our students's experience of online and blended learning.

\section{References}

Ahmed, J. \& Morley, G. (2010). VLE a blessing or a curse: VLE use by HE academic staff. In: Global Learn Asia Pacific 2010 - Global Conference on Learning and Technology, May, 17-20, 2010, Penant, Malaysia. Retrieved January 21, 2016, from http://eprints.hud.ac.uk/8901/

Bee, T. (2013) Making the Most Out of IT: Report to TELWG. Liverpool, England: Liverpool Guild of Students, University of Liverpool. Retrieved January 21, 2016 from http://s3-eu-west1.amazonaws.com/nusdigital/document/documents/5358/47f4c95448444c7b5d4a0fea01 7d193b/MTMOIT\%20Report\%20FINAL.pdf

CCCU. (2012). Technology Enhanced Learning and Teaching (TELT) Strategy 2012-2015. Canterbury, England: Canterbury Christ Church University.

CCCU. (2015). Learning, Teaching \& Assessment Strategy 2015-2020. Canterbury, England: Canterbury Christ Church University. Retrieved December 14, 2015, from http://www.canterbury.ac.uk/learning-and-teaching-enhancement/what-we-do/policiesand-resources/learning-teaching-and-assessment-strategy.aspx 
Chatterton, P. \& Rebbeck, G. (2015). Technology for Employability: Study into the role of technology in developing student employability. Bristol, England: Joint Information Systems Committee (JISC). Retrieved December 14, 2015, from http://repository.jisc.ac.uk/6249/3/Technology for_employability__full report.pdf

Ellis, R.A. \& Calvo, R.A. (2007). Minimum Indicators to Assure Quality of LMSsupported Blended Learning. Educational Technology \& Society, 10(2), 60-70. Retrieved January 21, 2016 from http://www.ifets.info/journals/10_2/6.pdf

Estes, J. (2013, October 27). Consistency in the Cross-Channel Experience. Nielson Norman Group (NN/g). Retrieved December 14, 2015, from https://www.nngroup.com/articles/cross-channel-consistency/

Gordon, N. (2014). Flexible Pedagogies: Technology-Enhanced Learning. York, England: The Higher Education Academy (HEA). Retrieved December 14, 2015, from https://www.heacademy.ac.uk/flexible-pedagogies-technology-enhanced-learning

HEFCE. (2015). National Student Survey (NSS). Bristol, England: Higher Education Funding Council for England (HEFCE). Retrieved January 21, 2016, from http://www.hefce.ac.uk/lt/nss/

Martin-Michiellot, S. \& Mendelsohn, P. (2000). Cognitive load while learning with a graphical computer interface. Journal of Computer Assisted Learning, 16(4), 284-293. doi:10.1046/j.1365-2729.2000.00141.x

Nielson, J. (2011, January 1). Top 10 Mistakes in Web Design. Nielson Norman Group $(N N / g)$. Retrieved December 14, 2015, from https://www.nngroup.com/articles/top-10mistakes-web-design/

Reed, P. (2014, March 21). Sector-wide subscription to VLE minimum standards. The Reed Diaries. Retrieved December 4, 2015, from http://thereeddiaries.blogspot.co.uk/2014/03/sector-wide-subscription-to-vleminimum.html

Reed, P. (2014, May 7). Minimum Standards / Baseline. Presentation of work around VLE Minimum Standards at the North West ALT SIG. Retrieved December 14, 2015, from http://www.slideshare.net/reedp/presentation-of-work-around-vle-minimum-standardsat-the-north-west-alt-sig-7514

Reed, P. \& Watmough, S. (2015). Hygiene Factors - Using VLE minimum standards to avoid student dissatisfaction. e-Learning and Digital Media, 12(1), 68-89. doi:10.1177/2042753014558379

Rovai, A.P. (2004). A constructivist approach to online college learning. The Internet and Higher Education, 7(2), 79-93. doi:10.1016/j.iheduc.2003.10.002

Stufflebeam, D.L. (2003). The CIPP Model for Evaluation. In: Kellaghan, T. \& Stufflebeam, D.L. (Eds.). The International Handbook of Educational Evaluation - Part One: Perspectives / Part Two: Practice. Boston, MA: Kluwer Academic Publishers, 31 62.

UoW. (2015). Digital Learning Thresholds. Wollongong, NSW, Australia: University of Wollongong (UoW). Retrieved January 22, 2016 from http://www.uow.edu.au/dvca/ltc/dlt/index.html 